\title{
NMR and FTIR Analysis of Overheated Cooking Oil
}

\author{
THÉONESTE MUHIZI* \\ University of Rwanda, School of Pure and Applied Science, \\ Department of Chemistry, University avenue 117 Butare, Rwanda. \\ *Corresponding author E-mail: tmuhizi@ur.ac.rw \\ http://dx.doi.org/10.13005/ojc/300233
}

(Received: March 06, 2014; Accepted: April 13, 2014)

\begin{abstract}
In this study, we combined different physico-chemical methods to show the effect of overheating on the quality of golden fry cooking oil. Those methods include spectroscopic methods such us ${ }^{1} \mathrm{H}$-NMR, ${ }^{13} \mathrm{C}-\mathrm{NMR}$ and FTIR. Results showed that both overheating and excessive reuse of golden fry cooking oil seriously affected its quality by increasing its density, viscosity and different indexes like refractive, saponification, esters, peroxide values and also by decreasing its iodine value. Both NMR and FTIR spectroscopic methods confirmed these changes and indicated the presence of some carbonyl compound derivatives in overheated samples.
\end{abstract}

Key words: Overheating, cooking oil, physico-chemical analysis, NMR, FTIR.

\section{INTRODUCTION}

Oils are one of natural compounds widely used by human for both social and economical issues. Due to their various origins, oils are chemically different so that their uses are also variable. Food preparation, cosmetic industries and artisanal lubricants are some wide domains in which they are used. Nowadays, there products are even largely needed to manufacture biodiesel, fuel with environmental friendly properties. In food preparation, cooking oils are used either for dressing, sautéing or frying food. Depending on what it is used for, cooking oil should be used differently to protect it against degradation. Its higher sensitivity to external factors such as heating, ultraviolet light, air and moisture may often cause its decomposition and leads to different problems in human body ${ }^{1-4}$. Nowadays, fried foods have become very popular to consumers due to their good flavour, colour and crispy texture ${ }^{3}$. However, during frying, not only a high temperature is applied on both oil and food, but also oil receives moisture from food leading to its rapid decomposition. Furthermore, frying is often conducted under air that accelerates oil degradation into different volatile and non volatile by-products with suspected toxicity. Thus the non volatile ones remain in the oil, change both physical and chemical properties and also negatively affect quality of foods. The presence of all these new elements in the oil undergoes further chemical reactions producing various compounds which affect its flavour stability, quality and texture. Finally, these suspected toxic compounds are absorbed with fried foods ${ }^{5}$ and this may constitute human intoxication risk. Carbonyls and free radicals, compounds with known toxicity ${ }^{6-8}$, are the major components of these. These compounds re 
known as precursor of different diseases in human body including cancer, atherosclerosis, inflammatory joint disease, asthma, diabetes, senile dementia and degenerative eye diseases ${ }^{9}$. To avoid these different health risks, frying method should be carefully controlled and type of cooking oil well chosen $^{5}$. Due to the ignorance of developing countries' people on the associated risks, fried cooking oil is often reused more times. Therefore, it is the responsibility of scientists to work hard in informing and advising people on both best practices in cooking and also on the quality of oil to use and this in the aim to avoid human intoxication. In this study, using both NMR and FTIR spectroscopies, we verified the effect of overheating on the quality of golden fry oil prior to conclude on its efficacy to resist on overheating process.

\section{EXPERIMENTAL}

\section{Sampling}

Golden fry oil (Bidco Uganda Limited, Uganda) was sampled from the students' restaurant of the University of Rwanda, Huye Campus, during frying potatoes. Before, sampling we were aware that cooks in this restaurant did not frequently discharge used oil but preferred to complete the remaining in fryers by the fresh one to make sufficient quantity for frying potatoes. For this reason, we started sampling with the first day of frying, directly after the beginning of the academic year where fryers didn't contain any reused oil. Three samples named $B, C$ and $D$, representing oils used for one, five and ten times respectively were collected. As reference, the unused oil was also sampled and named A. Before frying, temperature reached by oil was taken and noted. All samples were collected in opaque vials and kept at $0^{\circ} \mathrm{C}$ prior to be chemically analysed. They have been purified using decantation and filtration methods before further analysis.

\section{Determination of physico chemical parameters}

The density of samples was measured with a bottle pychnometer (Cole-Palmer) while the viscosity of samples was measured using a capillary viscosimeter (Cole-Palmer) using methods previously described ${ }^{10,11}$. Refractive, saponification, iodide, acid, ester and peroxide values were determined as described in the previous scientific reports $^{10-14}$.

\section{FTIR, ${ }^{1} \mathrm{H}$ NMR and ${ }^{13} \mathrm{C}$ NMR analysis}

FTIR spectra were recorded on PerkinElmer-Paragon 1000 PC spectrophotometer. Ten micro litres $(10 \mu \mathrm{L})$ of sample is spread between two $\mathrm{KBr}$ pellet discs previously fabricated and then spectra were recorded between 400 and $4000 \mathrm{~cm}$ ${ }^{1}$ using 50 scans at a resolution of $4.0 \mathrm{~cm}^{-1}$. ${ }^{1} \mathrm{H}$ NMR and ${ }^{13} \mathrm{C}$ NMR spectra were recorded at $300 \mathrm{MHz}$ on Bruker Avance 300 spectrometer. Chemical shifts are given in ppm.

\section{RESULTS AND DISCUSSION}

In this study, golden fry oil reached a flash point of $186^{\circ} \mathrm{C}$ prior to fry potatoes. According to different authors, this temperature is sufficient to highly decompose many frying oils into highly reactive agents ${ }^{15-18}$. Considering that frying was conducted in non covered cooking utensils, air was in direct contact with both oil and fried potatoes. Consequently, in conjunction with oxygen and other substances released from potatoes, these reactive agents accelerate further degradation of the oil and lead to the formation of various by products with suspected side effects on human health. Degradation of golden fry oil during frying was preliminary remarked through different colours obtained from samples which varied from clear yellowish, yellow orangey, yellow orangey to redorangey for samples $A, B, C$ and $D$, respectively (Figure 1).

This preliminary observation on the degradation of golden fry oil was confirmed by physicochemical characteristics of different samples analysed (Table 1). The density, viscosity, different values including refractive, saponification, acid, oxidised acids, ester and peroxide values were increased with time of heating. These suggested a possible degradation of the starting oil (sample A). The density varied from 0.933 to 0.9443 for the samples $A$ and $D$ respectively, while the viscosity changed from 5.2 to 5.9 for the samples $A$ and $D$ respectively. The increasing of these two parameters from sample $A$ to the overheated oil, sample $D$, may be in relationship, not only with chemical changes, especially the increasing of free fat acids in the oil, but also with some droplet released into the re-used 
oil $^{10}$. Refractive value increased from 1.473 to 1.568 for samples $A$ and $D$ respectively, while iodide valuedecreased from 122 to 108 for $A$ and $D$ samples respectively. These changes may suggest a polymerisation or an oxidation of the starting oil during its heating and re-using ${ }^{12}$. Furthermore, increasing of both saponification and acid values may indicate a relationship between heating and formation of free fatty acids. Higher index values in the more heated oil may indicate that oil was hydrolysed during heating.

Table 1: Physico chemical characteristics of different samples of golden fry oil

\begin{tabular}{|c|c|c|c|c|}
\hline \multirow[t]{2}{*}{ Parameters } & \multicolumn{4}{|c|}{ Different samples' values } \\
\hline & A & B & C & D \\
\hline Density & 0.933 & 0.934 & 0.936 & 0.943 \\
\hline Viscosity (cP) & 5.20 & 5.23 & 5.30 & 5.9 \\
\hline Refractive index & 1.473 & 1.472 & 1.476 & 1.568 \\
\hline Saponification value $\left(\mathrm{mg} \mathrm{g}^{-1}\right)$ & 187 & 188.8 & 193.7 & 197 \\
\hline lodine number & 122 & 120.5 & 118 & 108 \\
\hline Acid index $\left(\mathrm{mg} \mathrm{g}^{-1}\right)$ & 0.74 & 1.09 & 3.23 & 4.15 \\
\hline Peroxide index (mEq) & 1.60 & 6.45 & 17.98 & 20.6 \\
\hline Ester index $\left(\mathrm{mg} \mathrm{g}^{-1}\right)$ & 186.26 & 187.71 & 190.20 & 192.85 \\
\hline Percentage of oxidised acids (\%) & 0.20 & 1.40 & 2.60 & 3.90 \\
\hline
\end{tabular}

Table 2: Attribution of some absorption bands from oil samples

\begin{tabular}{ll}
\hline Wave numbers $\left(\mathbf{c m}^{-1}\right)$ & Attribution \\
\hline 3610 & Absorption of $-\mathrm{OH}$ groups \\
3472 & $\mathrm{C}-\mathrm{H}$ for alkenes elongation \\
$3008-2857$ & Symmetric and asymmetric vibration of $\mathrm{C}-\mathrm{H}, \mathrm{H}-\mathrm{C}-\mathrm{H}$ et $-\mathrm{CH}_{3}$ \\
1742 & Elongation vibration of $\mathrm{C}=\mathrm{O}$ from carbonyl groups \\
1653 & $\mathrm{C}=\mathrm{C}$ elongation \\
$1457-1096$ & Various absorption bands of alkyl chains (symmetric and asymmetric angular \\
& deformation of $-\mathrm{CH}_{2}$ - et $-\mathrm{CH}_{3}$ ) \\
$1026 \mathrm{~cm}^{-1}$ & absorption bands of cis- double bond angular deformation \\
856 & absorption bands of trans- double bond angular deformation \\
724 & Rocking of $-\mathrm{CH}_{2}-$ group \\
\hline
\end{tabular}

Table 3: Chemical shifts of different protons found in samples A and D

\begin{tabular}{ll}
\hline Chemical shift (ppm) & Attribution \\
\hline 0.9 & $-\mathrm{CH}_{3}$ (olefenic chain) \\
1.28 & $-\mathrm{CH}_{2}-$ (zone $\left.\mathrm{E}\right)$ \\
1.56 & $-\mathrm{CH}_{2}-($ zone $\mathrm{D})$ \\
2.01 & $-\mathrm{CH}_{2}-($ zone $\mathrm{F})$ \\
2.30 & $-\mathrm{CH}_{2}-($ zone $\mathrm{C})$ \\
2.75 & $-\mathrm{CH}_{2}-($ zone $\mathrm{H})$, was not detected in sample D \\
$4.30-4.10$ & $-\mathrm{CH}_{2}-,-\mathrm{CH}-($ zones A et $\mathrm{B})$ \\
5.32 & $-\mathrm{HC}^{2} \mathrm{CH}-($ zone G) \\
7.25 & $\mathrm{CD}_{3} \mathrm{Cl}$ \\
\hline
\end{tabular}


These results corroborate with literature which reported that hydrolysis of triglycerides should be accompanied by the increasing of free fatty acids in the oil ${ }^{10,19}$. lodide value was decreased with time of heating and re-using and this was closely related to the decreasing number of double bonds initially composing unused oil. This phenomenon may be due to the oxidation process of olefin bonds conducting to the formation of polar compounds in

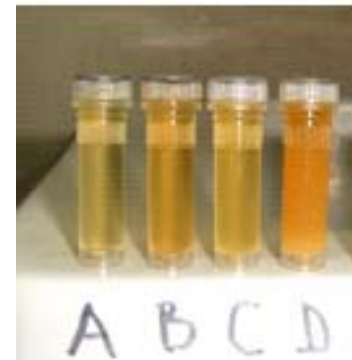
A: The starting ail
B: Oil heated for chiere
C. Oil heated for five ti mes
D: Oil hexed for ten times

Fig. 1: Colours of samples analysed the re-used oil ${ }^{10}$. The increasing of acid, peroxide, ester, oxidised acids values in the oil confirmed and supported this suggestion.

\section{FTIR, ${ }^{1} \mathrm{H}$ NMR and ${ }^{13} \mathrm{C}$ NMR characteristics}

In Fourier Transform Infrared (FTIR) spectroscopy, four samples A, B, C and D indicated big ressemblances at short waveleghts. However at wavelenghts of 1653 and $3472 \mathrm{~cm}^{-1}$ only sample A absorbed while there was no absorbance for samples $B, C$ and D. Furthermore, at $3610 \mathrm{~cm}^{-1}$, samples $B, C$ and $D$ largely absorbed while sample A did not (Figure 2).

In FTIR spectra (Figure 2), sample A, presented an absorption band at $3472 \mathrm{~cm}^{-1}$ indicating $\mathrm{C}-\mathrm{H}$ for alkenes elongation. This band was confirmed by other absorption band remarked at $1653 \mathrm{~cm}^{-1}$ indicating $\mathrm{C}=\mathrm{C}$ elongation. These two absorption bands were not observed from samples

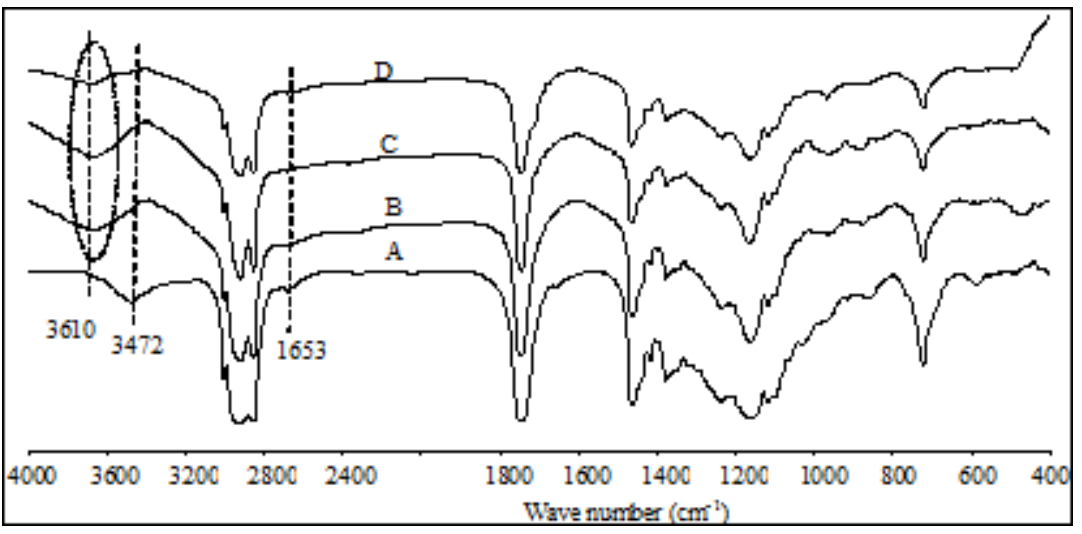

Fig. 2: FTIR spectra of different oil samples

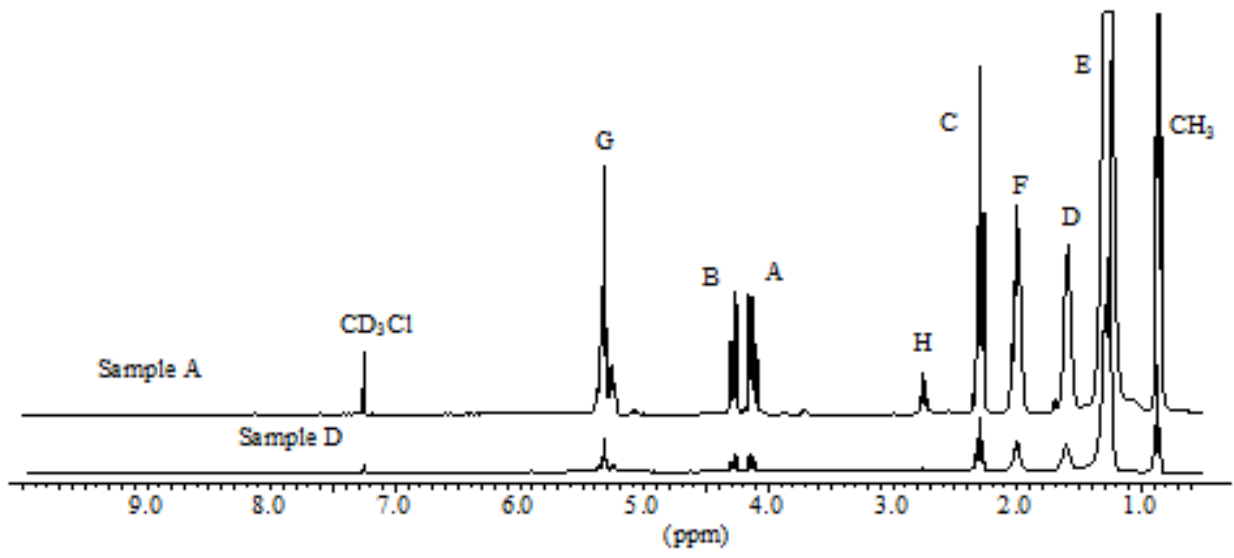

Fig. 3: ${ }^{1} \mathrm{H}$ NMR spectra of sample $A$ and $D$ 
B, C and D. Furthermore, heated oils (samples B, C and D) presented absorption band at $3610 \mathrm{~cm}^{-1}$ which band was not detected from sample $A$. These differences remarked between unused oil and heated samples in IR absorption may indicate hydrolysis of triglyceride: break down of ester bonds actually found in sample A and release of glycerol, mono/di- acyl glycerol and fat acid. The later compounds are found in samples B, C and D. Glycerol, mono/di- acyl glycerol contain free $\mathrm{OH}$ groups and are able to absorb around $3610 \mathrm{~cm}^{-1}$ as remarked in IR spectra ${ }^{20}$.

Findings from FTIR spectroscopy were confirmed by both proton and carbon nuclear magnetic resonance ( ${ }^{1} \mathrm{H}$ NMR and $\left.{ }^{13} \mathrm{C} N M R\right)$ spectroscopy. Signals of ${ }^{1} \mathrm{H}$ NMR spectra of both samples $A$ and $D$ (Figures 3 and 4 ) indicated that golden fry oil is mainly composed by a triglyceride of linoleic acid. ${ }^{1} \mathrm{H}$ NMR pics were attributed to different protons of this triglyceride as shown in the table 3. These results from NMR spectroscopy confirmed those from other methods previously used.

A comparison done between ${ }^{1} \mathrm{H}$ NMR of samples $A$ and $D$ (Figure 3 ) indicated that signal at 2.75 ppm (zone $\mathrm{H}$ ) was absent from sample $\mathrm{D}$. This signal represents two protons of $\mathrm{C}-\mathrm{H}$ separating two double bonds of linoleic acid as previously reported ${ }^{21,22}$. Its absence from sample $D$ confirmed the break down of double bonds of linoleic acid leading to the formation of other products. Further analysis of ${ }^{1} \mathrm{H}$ NMR spectra, at chemical shifts varying between 7.2 and 10.4 ppm where signals of carbonyl group may be appeared, indicated clear differences between heated oils and unused one (Figure 5). In addition, comparison done between samples $A$ and $D$ at chemical shifts of 5.6-8.4 ppm indicated also new signals in sample D (Figure 5). Zoomed zones showed new signals from all overheated and reused oils (samples B, C and D)

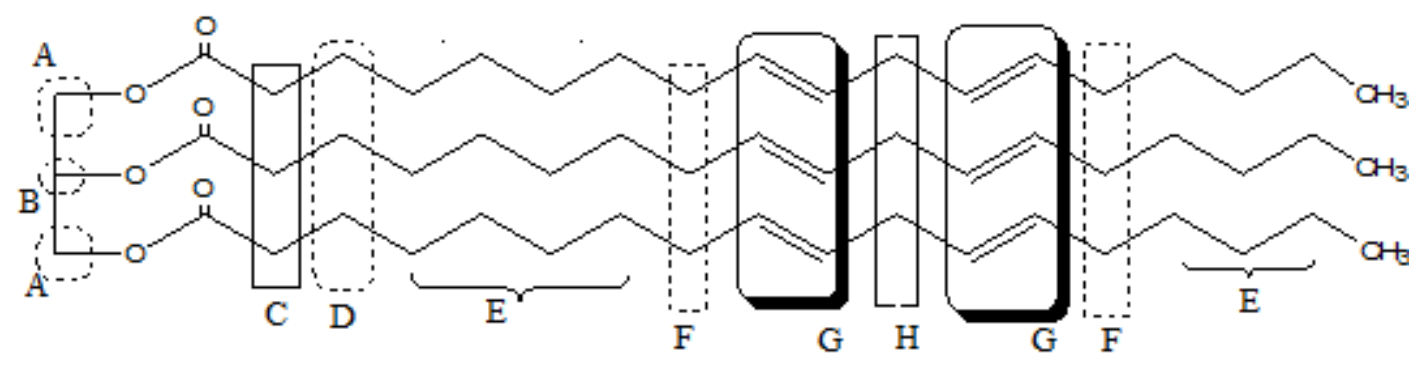

Fig. 4: Triglyceride of linoleic acid
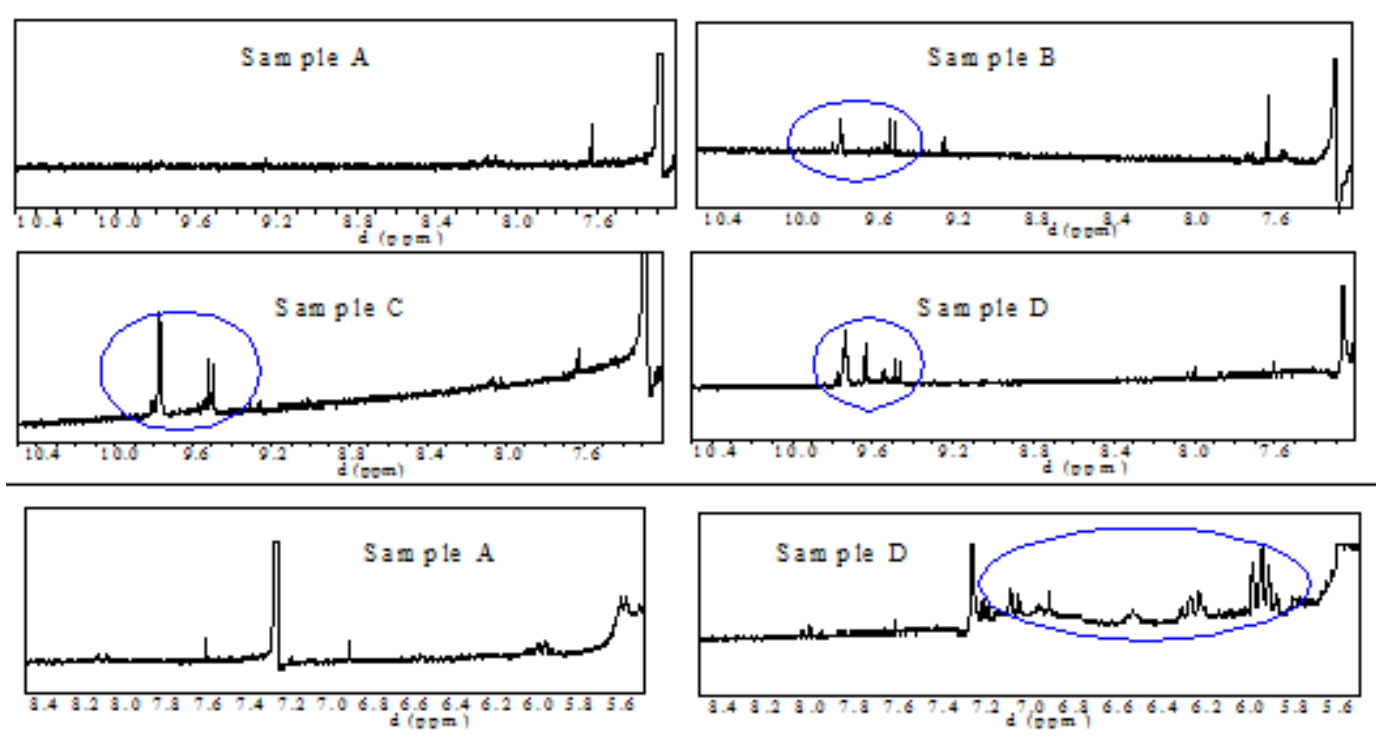

Fig. 5: ${ }^{1} \mathrm{H}$ NMR difference between unused oil and overheated and reused oils 
at $\Sigma_{H}$ 9.4-9.8 ppm and at $\Sigma_{H}$ 5.8-7.2 ppm and this comparatively to the sample $A$. These signals may indicate formation of aldehydic or acidic group of compounds in these overheated oils ${ }^{20}$.

In ${ }^{13} \mathrm{C}$ NMR spectra and comparatively to the spectrum of sample $A$, new signals were detected from overheated samples around the chemical shifts of $170,174.5$ and $181 \mathrm{ppm}$ for sample D, 179 ppm for samples B, C and D, and $189.5 \mathrm{ppm}$ for samples $\mathrm{C}$ and D. These ${ }^{13} \mathrm{C}$ NMR findings corroborated with results from ${ }^{1} \mathrm{H}$ NMR and indicated the presence of carbonyl groups such as aldehydic and acidic compounds in analysed samples $^{20}$. Sample D which was from the more reused oil, was the more decomposed, it presented new broad signals at chemical shifts varying between 5.8 and $7.2 \mathrm{ppm}$ in ${ }^{1} \mathrm{H}$ NMR and also new signals at $170,174.5$ and $181 \mathrm{ppm}$ in ${ }^{13} \mathrm{C}$ NMR, which signals were absent from other samples. These polar compounds may be formed during heating where oxidation of double bonds and hydrolysis of ester bonds in the overheated samples took place. According to some authors, during heating, water, vapours and oxygen induced different chemical reactions in the fried oil, and these lead to the formation of different chemical oxidants ${ }^{9}$, ${ }^{5}$. As nucleophile compound, water is able to attack ester bond of triglyceride and lead to the production of a mixture of free fatty acids, glycerol and mono-, di- and acyl- glycerol in the used oil. Furthermore, times of re-using cooking oil are also closely in relationship with its decomposition ${ }^{23,24}$. Through spectroscopic methods, this study showed that after one time of use, golden fry oil was degraded. This higher degradation under heating may be due to the presence of linoleic acid in the oil since it was reported that oils mainly composed by linoleic acids are more easily polymerised during frying than those containing oleic acids ${ }^{23-25}$. The presence of carbonyl groups in overheated oil may constitute a serious risk to the human body. It was reported that aldehydes are potentially toxic substances with possibility to induce different cancers when consumed $^{26-28}$. Furthermore, it is known that asparagine and reducing sugars are relatively in high amount in potatoes, and that both compounds are the main precursors of acrylamide, which is formed during frying, baking, grilling or toasting carbohydrates rich foods ${ }^{19,29,30}$. For this reason, signal observed at $181 \mathrm{ppm}$ in ${ }^{13} \mathrm{C}$ NMR spectrum of sample D may represent this compound. However further studies are required to well analyse and illustrate all by-products formed for conclusion. Note that acrylamide is considered as neurotoxic and classified as probably carcinogenic to humans by the International Agency for Research on Cancer ${ }^{19}$, 29,30 .

\section{CONCLUSION}

All cooking oils, especially those used during frying should be discharged after one time of use to avoid consuming toxic compounds together with food. This study showed that heating oil at higher temperature for only one time is sufficient to break down its double bonds, even with possibility to lead to the formation of harmful compounds. Consequently, fried foods should be consumed with care and in moderate manner while golden fry oil assessed in this study may not be preferred as frying oil but can be used for other cooking services that don't require high temperature.

\section{ACKNOWLEDGMENTS}

We are very grateful to the University of Rwanda, especially the Research Commission to allow realization of this research and Mrs Pacifique Umubyeyi for technical assistance.

\section{REFERENCES}

1. Brown W., Rogers E., General Organic Biochemistry, Williard Grant Press, Boston, 1980; 811.

2. Soriguer F., Rojo-Martinez G., Dobarganes M. C., Almeida J. M. G., Esteva I., Bertran M., De Adana M.S.R., Tinahones F., Gomez-
Zumaquero J.M., Garcia-Fuentes E., Gonzalez-Romero S., Am. J. Clin. Nutr. 2003; 78: 1092.

3. Boskou D., Salta F. N., Chiou A., Troullidou E., Andrikopoulos N. K., Eur. J. Lip. Sci. Tech. 2006; 108: 109.

4. Mestdagh F., Castellan P., De Meulenaer B., 
Van Peteghem C., J. Agric. Food Chem 2008; 56(15): 6141.

5. Choe E., Min D. B., J. Food Sci. 2007; 72(5): 77.

6. Stohs S. J., J. Basic Clin. Physiol. Pharmacol., 1995; 6(3-4): 205. Find all citations by this author (default). Or filter your current search

7. Dellinger B., Pryor W. A., Cueto R., Squadrito G. L., Hegde V., Deutsch W. A., Chem. Res. Toxicol. 2001; 14(10): 1371. Find all citations in this journal (default).

8. O’Brien P.J., Siraki A. G., Shangari N., Crit. Rev. Toxicol. 2005; 35(7): 609.

9. Bagchi K., Puri S., East. Mediterr. Health J. 1998; 4(2): 350.

10. Noirfalise A., Foussin A., Méthodes d'analyse des substances alimentaires. $4^{\text {ème }}$ édition, Université de Liège, 1981; 282.

11. Audigie C., Figarella J., Zonszain F., Manipulations d'analyse biochimique, Doin Editeurs, Paris, 1982; 274.

12. Gautier J. A., Pellerin F., Renault J., Fiches techniques d'analyse bromatologique. Société d'édition d'enseignement supérieure, Imp. Jouve, Paris, 1961; 230.

13. OMS, Méthodes générales d'analyse,

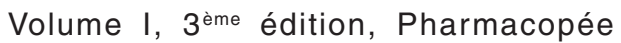
internationale, Genève, 1980; 860.

14. Solomon S., General Organic and Biological Chemistry, McGraw-hill Inc., USA, 1987; 845.

15. Lin J. M., Liou S. J., Bull. Environ. Contam. Toxicol. 2000; 64: 817.

16. Ndjouenkeu R., Ngassoum M., J. Food Eng., 2002; 52(2): 121.

17. Gertz C., Klostermann S., Eur. J. Lip. Sci. Tech. 2002; 104: 762.
18. Nglum C., Wehling R. L., Cuppett S. L., J. Agric. Food Chem 2007; 55: 593.

19. Mestdagh F., De Meulenaer B., Van Peteghem C., J. Agric. Food Chem 2007; 100: 1153.

20. Silverstein M. R., Clayton B. G., Morill T. C., Larue E., Schanck A. Identification spectrométrique des composés organiques. De Boeck Université, Paris, 1998; 432.

21. Ogawa J., Mastumura K., Kishino S., Omura Y., Shimizu S., Appl. Envir. Microbiol., 2001; 67(3): 1246.

22. Ying C., Lin Y., Hong-Li G., Jing-Nan C., ZhenYu C., Qiu-Shi R., Chem. Phys. Lipids 2007; 145: 128. Find all citations by this author (default).

23. Takeoka G. R., Full G. H., Dao L. T., J. Agric. Food Chem 1997; 50: 4998.

24. Tompkins C., Perkins E. G., J. American Oil Chemists' Society 2000; 77: 223.

25. Bastida S., Sanchez-Muniz F. J., Food Sci. Technol. 2001; 7: 15.

26. Wang R., Nakajima T., Kawamoto T., Honma T., Drug Metab. Dispo. 2002; 30(1): 69.

27. Yokoyama T., Yokoyama A., Kato H., Tsujinaka T., Mute M., Omori T., Haneda T., KumagaiY., Igaki H., Yokoyama M., Watanabe H., Yoshimizu H., Cancer Epidemiol. Biomarkers Prevent. 2003; 12(1): 1227.

28. Boccia S., Hashibe M., Galli P., De Feo E., Asakage T., Hashimoto T., Hiraki A., Katoh T., Nomura T., Yokoyama A., van Duijn C., Ricciardi G., Boffetta P., Cancer Epidemiol. Biomarkers Prevent. 2009; 18(1): 248.

29. Pedreschi F., Moyano P., Kaack K., Granby K., Food Res. Int. 2005; 38: 1.

30. IARC, Acrylamide, International Agency for Research on Cancer, Lyon, France, 1994. 